\title{
Evasão escolar no ensino superior: um estudo qualitativo via mapeamento de licenciaturas
}

\author{
Thays Santos Souza, Susana Sá \& Paulo \\ Alexandre de Castro
}

\begin{abstract}
Resumo:
Realizou-se uma investigação qualitativa sobre a evasão dos cursos (presenciais) de licenciaturas em Física, Matemática e em Química da Universidade Federal de Goiás (UFG). Considera-se evadido o estudante que abandona(ou)/desiste(iu) do curso no qual está matriculado antes de concluí-lo. O objetivo principal deste estudo foi mensurar e compreender a realidade da evasão nos cursos de graduação presenciais da UFG. Os cálculos de evasão foram consolidados para o período de 2014 a 2016, a partir de duas fórmulas: a primeira estipulada pela Comissão Especial de Estudos sobre evasão; e a segunda utilizada pelo grupo de trabalho do Fórum de Pró-reitores de Planeamento e Administração. Com a finalidade de obtenção de dados, foram aplicados quatro questionários (instrumentos de recolha de dados validados), com questões abertas e fechadas. Entre os principais motivos que levaram/levam os estudantes a abandonar o curso foram apontados: os professores, a coordenação, o ensino e as aulas. Concluiu-se que a trajetória académica é definida sob ponto de vista (pressão) social, os estudantes não escolhem o curso por vocação, mas sim por influências exógenas ou outras razões tais como relações pessoais e/ou profissionais.
\end{abstract}

Palavras-chave:

evasão; ensino superior; investigação qualitativa. 


\title{
School dropout in higher education: a qualitative study by the mapping of undergraduate courses
}

\begin{abstract}
A qualitative investigation was carried out on the dropout of (presential) undergraduate degree courses in Physics, Mathematics and Chemistry of the Federal University of Goiás (UFG). A student who leaves (or) / gives up of the course in which is enrolled before completing it is considered dropout. The main objective of this study was to measure and understand the reality of dropout in UFG presential undergraduate courses. The dropout calculations were consolidated for the period 2014 to 2016, from two formulas: the first being proposed by the Special Committee on Dropout Studies; and the second one used by the Pro-Rectors for Forum of Pro-Rectors for Planning and Administration. In order to obtain data, four questionnaires (validated data collection instruments) were applied, with open and closed questions. Among the main reasons that led the students to leave the course are: teachers, coordination, teaching and classes. It is concluded that the academic trajectory is defined from a social (pressure) point of view, students do not choose the course by vocation, but by exogenous influences or other reasons such as personal and /or professional relationships.
\end{abstract}

Keywords: dropout; higher education; qualitative research.

\section{Décrochage dans l'enseignement supérieur: une étude qualitative dans des cours de licence}

Résumé: Cette recherche qualitative a été réalisée sur le décrochage dans les cours (présentiels) de licence de en Physique, Mathématique et Chimie de I'Université Fédérale de Goiás (UFG) au Brésil. Est considéré comme évadé, l'étudiant qui abandonne (ou a abandonné)/désiste (a désisté) du cours dans lequel il s'est inscrit avant sa conclusion. L'objectif principal de cet étude était de mesurer et de comprendre la réalité de l'évasion dans les cours de licence présentiels de I'UFG. Les calculs de l'évasion ont été consolidés sur la période 2014 à 2016 à partir de deux formules: la première stipulée par la Commission Spéciale des Études sur l'Evasion; et la seconde utilisée par le groupe de travail du Forum des vices recteurs de planification et de gestion. Dans le but d'obtenir des données, quatre questionnaires (instruments de cueillette de données validées) ont été appliquées avec des questions ouvertes et fermées. Parmi les principaux motifs qui emmènent ou ont poussé les étudiants à abandonner les cours on note: les enseignants, la coordination, l'enseignement et les cours en tant que tels. On peut conclure que la trajectoire académique est définie au point de vue (pression) sociale, les étudiants ne choisissent pas les formations par vocation, mais par influences exogènes ou d’autres motifs tels que les relations personnelles et/ou professionnels.

Mots-clés: évasion; enseignement supérieur; recherche qualitative.

\section{El abandono escolar en la educación superior: un estudio cualitativo para el mapa de grados}

Resumen: Se realizó una investigación cualitativa sobre la evasión de los cursos (presenciales) de licenciaturas en Física, Matemática y en Química en la Universidad Federal de Goiás (UFG). Se considera evadido el estudiante que abandona / desiste o ha desistido del curso en el que era matriculado antes de concluirlo. El objetivo principal de este estudio fue medir y comprender la realidad de la evasión en los cursos de graduación presenciales de la UFG. Los cálculos de evasión se consolidaron para el período 2014 a 2016, a partir de dos fórmulas: la primera estipulada por la Comisión Especial de Estudios sobre la evasión; y la segunda utilizada por el grupo de trabajo del Foro de Prorectores de Planificación y Administración. Con el fin de obtener datos, se aplicaron cuatro cuestionarios (instrumentos de recogida de datos validados), con preguntas abiertas y cerradas. Entre los principales motivos que llevaron a los estudiantes a abandonar el curso fueron apuntados: los profesores, la coordinación, la enseñanza y las clases. Se concluyó que la trayectoria académica es definida desde el punto de vista social, los estudiantes no escogen el curso por vocación, sino por influencias exógenas u otras razones tales como relaciones personales y / o profesionales.

Palabras-clave: evasión; enseñanza superior; investigación cualitativa. 


\section{Introdução}

Para o Ministério de Educação (MEC), evasão "é a saída definitiva do curso de origem sem conclusão, ou a diferença entre ingressantes e concluintes, após uma geração completa". (Ministério da Educação/Secretaria de Educação Superior [MEC/ SESu], 1997). É possível concetualizar a evasão nos seguintes níveis: a) de curso; b) da instituição e c) do sistema.

Veloso (2000) afirma que a evasão é um fenómeno complexo, comum às instituições universitárias no mundo contemporâneo. Nos últimos anos, este tema tem sido estudado e analisado, especialmente nos países do primeiro mundo, e têm demonstrado não só a universalidade do fenómeno como a relativa homogeneidade do seu comportamento em determinadas áreas do saber, apesar das diferenças entre as instituições de ensino e das peculiaridades socioeconómicas e culturais de cada país. A evasão académica é um problema que deve ser tratada através de uma abordagem sistémica. A meta básica não é, simplesmente, manter os estudantes nas salas de aula até que concluam as suas licenciaturas, mas sim oferecer a esses alunos uma educação que os prepare para uma vida plena e produtiva.

De acordo com Ruiz, Ramos e Hingel (2007), um estudo realizado pela Confederação Nacional dos Trabalhadores em Educação (CNTE) apontou que a evasão nas Universidades brasileiras é uma realidade que se vem intensificando no decorrer do tempo. Em vários cursos do ensino superior as taxas (os índices) de evasão estão cada vez mais elevadas, acarretando assim (ou ao menos contribuindo e muito) para a escassez, e dependendo da região do Brasil, na falta de professores com formação adequada para ingressar no mercado de trabalho, seja nos níveis fundamental e médio, o que é preocupante. Esse cenário é retratado na tabela 1, que apresenta os índices de evasão nos cursos de licenciatura, no Brasil, segundo relatório do estudo da escassez de professores (como formação adequada ou não) no ensino médio (Ruiz, Ramos \& Hingel, 2007). 
Tabela 1 - Evasão nos Cursos de Licenciatura no Brasil, em 1997

\begin{tabular}{lc}
\hline Curso & Evasão média \\
\hline Química & $75 \%$ \\
Física & $65 \%$ \\
\hline Matemática & $56 \%$ \\
Biologia & $42 \%$ \\
\hline História & $44 \%$ \\
Geografia & $47 \%$ \\
\hline Letras & $50 \%$ \\
\hline Educação Artística & $52 \%$ \\
\hline
\end{tabular}

Fonte: Ruiz et al. (2007)

Na tabela 1, são apresentados valores médios da evasão de alguns dos cursos de licenciatura no Brasil. Para identificação dessas percentagens, foi utilizado o método de cálculo sugerido (e utilizado em 1995) pela Comissão Especial de Estudos sobre Evasão (CEEE).

\section{Possíveis Causas da Evasão no Ensino superior}

Após a realização de uma revisão da literatura, identificaram-se vários fatores que poderiam justificar os altos índices de evasões, tanto de ordem interna quanto externa à instituição de ensino. Entre os fatores identificados, as causas económicas e sociais refletem a existência de problemas à margem das instituições e que, portanto, independem das decisões dos gestores educacionais, enquanto que as causas consideradas internas podem/devem ser geridas para se reduzir as causas da evasão.

Tinto (1975) defendeu que o estudante chega(va) à Universidade com objetivos pré-estabelecidos conforme as suas necessidades pessoais, sejam elas motivadas pela sua condição financeira, expetativa dos pais, crenças e valores além das suas características pessoais. E, ao longo da vivência académica, os estudantes definem se persistem ou desistem da sua escolha profissional. O fenómeno de evasão é complexo e deve-se a diversos fatores internos (relativos às instituições) e externos (relativos aos alunos). Os fatores internos estão relacionados com a instituição, ao curso, e podem ser classificados em: infraestrutura, corpo docente e a assistência socioeducacional. Os fatores externos relacionam-se diretamente com os alunos, tais como: vocações, aspetos socioeconómicos e problemas de ordem pessoal. Alunos/estudantes que iniciam um curso de graduação e desistem causam prejuízos/desperdícios sociais, 
académicos e económicos. Para além destes problemas, a evasão causa ociosidade de professores, funcionários, equipamentos e espaço físico.

Num estudo realizado por Andriola (2003), foram ouvidos evadidos dos cursos de graduação da Universidade Federal do Ceará - UFC, e, na sua maioria, afirmaram que escolheram o curso por afinidade com a área e que desistiram por alguns dos seguintes motivos: a) incompatibilidade de horário (estudo e trabalho); b) problemas familiares e c) precariedade das condições oferecidas pela Universidade (estrutura física e estrutura curricular dos cursos).

Por outro lado, e não menos importante, os grupos que compõem a sociedade evoluem a uma grande velocidade e os jovens/estudantes estão no centro dessa evolução. Destes estudantes é esperado, quando não é exigido (pelos seus pais e/ou parentes, ou por pressão de um outro grupo social), a escolha/decisão certeira de uma profissão. Assim, selecionar uma licenciatura com base num conjunto de habilidades e competências (ou no desconhecimento delas) talvez se torne cada vez mais difícil nos dias de hoje. Em parte, isso se deve ao facto de que, atualmente, na grande maioria das escolas, colégios e universidades não haver mais profissionais responsáveis pela orientação pedagógica/vocacional dos estudantes, com acompanhamento psicológico e testes vocacionais para auxiliar os estudantes a descobrirem qual(is) os cursos mais adequados às suas habilidades e competências.

Bergamo e colaboradores (2008) verificaram, na sua investigação, que os principais aspetos citados pelos estudantes na escolha da IES (Instituições de Ensino Superior), foram: a)localização; b) tradição; c) empregabilidade; d) aspetos sociais; e) fatores financeiros; f) qualidade; g) infraestrutura e h) atmosfera do Campus.

Bardagi e Hutz (2008) trouxeram outro olhar para a questão da evasão, o lado do apoio familiar, a importância do apoio dos pais na escolha profissional do estudante, realçando a participação da família na decisão da evasão do curso. No final da pesquisa verificou-se que os pais são as maiores referências no âmbito familiar da escolha vocacional dos jovens. Ainda hoje, é bastante frequente relatos de estudantes que afirmam que não possuem livre diálogo com seus pais/famílias sobre esse tema. Diante desse cenário, os estudantes, muitas vezes, se sentem solitários tanto no momento da escolha profissional quanto no momento de saída do curso.

Carvalho e Tafner (2006) apresentaram dez possíveis causas da evasão:

- Impossibilidade de estudar e trabalhar ao mesmo tempo;

- Pouco envolvimento no curso gratuito;

- Simultaneidade de dois cursos superiores e opção por um outro;

- Vocação errada ou informações prévias insuficientes;

- Greve prolongada de professores;

- Deceção com o curso e críticas às deficiências do mesmo; 
- Casamento e novas obrigações sociais;

- Imaturidade - entrou muito jovem na universidade;

- Dificuldades académicas e rigidez excessiva dos professores;

- Falta de perspetivas no exercício da profissão.

Na sequência deste artigo, procurando robustez na análise dos dados e consequentemente das considerações a serem obtidas, realizou-se um exame minucioso das percentagens de evasão, para além de uma análise qualitativa das respostas às questões abertas dos questionários que foram aplicados.

\section{Opções metodológicas}

\subsection{Metodologia para dos cálculos das taxas de evasão dos cursos de licenciaturas da UFG}

Verificou-se que existiam alguns indicadores que permitem calcular a evasão que foram encontrados em estudos realizados por Tinto (1975), MEC/SESu (1997) e Nunes (2013). Este tópico tem como finalidade apresentá-los e mostrar o que foi considerado em cada uma das metodologias do cálculo.

As metodologias do cálculo para evasão na educação superior no Brasil compõem uma temática que apresenta certas indefinições, contudo ainda existem algumas questões, tais como, se algumas definições/considerações/questões adotadas em IES de outros países são adequadas para o contexto das IES brasileiras. Sendo assim, a realização de estudos sobre esse tema (evasão) é essencial para encontrar soluções sólidas para a discussão e contribuir para a melhoria da qualidade na educação do ensino superior.

Procurou-se entender o comportamento da evasão nos cursos presenciais de graduação da UFG, assumiu-se a identificação dos índices de evasão nas licenciaturas selecionadas, em todas as regionais da Universidade que oferecessem cursos de licenciaturas. Foram apurados os dados necessários para composição das fórmulas escolhidas através do banco de dados do Sistema Integrado de Gestão de Atividades Acadêmicas (SIGAA). No final, elaborou-se uma plataforma eletrónica com a compilação dos dados de evasão anual dos cursos de graduação (na modalidade presencial) em Física, Matemática e Química da UFG, entre os anos de 2014 e 2016. Os cálculos das taxas de evasão foram realizados a partir de, originalmente, duas fórmulas: 1) fórmula sugerida pela Comissão Especial de Estudos sobre Evasão (CEEE); 2) fórmula proposta pelo Fórum de Pró-reitores de Planejamento e Administração (FORPLAD). A primeira fórmula foi sugerida pela CEEE, comissão que foi constituída em 1995, com 
intuito de unificar/padronizar a medida dos índices de evasão nas Instituições de ensino superior no Brasil. (MEC/SESu, 1997).

Para a comissão CEEE, o cálculo de evasão se expressa, pela Equação 1,

$$
\% \text { Evasão }=\frac{N i-N d-N r}{N i} * 100,
$$

onde: é o número de ingressantes; é o número de diplomados; é o número de retidos. Para o, foram consideradas as matrículas que se encontravam na situação de matrícula trancada. O número de retidos foi obtido através do Relatório de Atividades do Centro de Gestão Acadêmica (CGA) dos anos de 2014 a 2016.

A segunda fórmula para o cálculo dos índices de evasão foi sugerida pelo estudo realizado em 2007 (Filho, Motejunas, Hipólito, \& Lobo, 2007) e utilizada pelo grupo da FORPLAD, em 2015, para um estudo que tinha como um dos objetivos identificar a taxa de sucesso, evasão e retenção nas IFES do Brasil, realizado em âmbito nacional.

O cálculo foi realizado utilizando a equação 2 .

$$
E v_{p}=\left(1-\frac{M_{p}-I_{p}}{M_{p-1}-C_{p-1}}\right) * 100,
$$

onde: é o número de matriculados; é o número de ingressantes no período ; e e são os números de matriculados e o de concluintes no período anterior, respetivamente.

\subsubsection{Evasão dos cursos de licenciatura em Física, Matemática e Química na UFG, entre os anos de 2014 e 2016}

A seguir apresentaram-se as taxas de evasão encontradas no período de 2014 a 2016. Na última coluna das tabelas 2 e 3, foram explicitados os valores de evasão média por curso, no período estudado. As tabelas 2 e 3 (apresentadas a seguir) tiveram como principal objetivo agrupar os dados que demonstraram uma visão global do fenómeno estudado.

\subsubsection{Evasão média por curso a partir da coleta de dados}

Nas tabelas 2 e 3, foram apresentados os cálculos de evasão dos cursos (presenciais) dos seguintes cursos de licenciatura: Física, Matemática e Química das Regional de Catalão, Jataí e Goiânia da Universidade Federal de Goiás, de acordo com as Equações 1 e 2 . 
Tabela 2 - Taxas de evasão por curso (em ordem alfabética) e de evasão média anual, entre os anos de 2014 a 2016, de acordo com a fórmula da CEEE.

*TE/14 = taxa de evasão no ano de 2014,

**TE/15 = taxa de evasão no ano de 2015,

***TE/16 = taxa de evasão no ano de 2016

\begin{tabular}{|c|c|c|c|c|c|c|c|}
\hline $\begin{array}{l}\text { Regional/ } \\
\text { Câmpus }\end{array}$ & Curso & $\begin{array}{c}\text { Grau } \\
\text { Acadêmico }\end{array}$ & Turno & TE/14* & TE/15** & $\begin{array}{c}\mathrm{TE} / 16^{* *} \\
*\end{array}$ & $\begin{array}{l}\text { Evasão } \\
\text { média }\end{array}$ \\
\hline Catalão & Física & Lic. & Not. & $63 \%$ & $90 \%$ & $47 \%$ & $67 \%$ \\
\hline Catalão & Matemática & Lic. & Not. & $85 \%$ & $76 \%$ & $31 \%$ & $64 \%$ \\
\hline Catalão & Química & Lic. & Not. & $67 \%$ & $11 \%$ & $8 \%$ & $29 \%$ \\
\hline Jataí & Física & Lic. & Not. & $88 \%$ & $92 \%$ & $62 \%$ & $81 \%$ \\
\hline Jataí & Matemática & Lic. & Not. & $76 \%$ & $86 \%$ & $14 \%$ & $59 \%$ \\
\hline Jataí & Química & Lic. & Not. & $73 \%$ & $91 \%$ & $53 \%$ & $72 \%$ \\
\hline Goiânia & Física & Lic. & Int. & $81 \%$ & $100 \%$ & $100 \%$ & $94 \%$ \\
\hline Goiânia & Física & Lic. & Not. & $40 \%$ & $77 \%$ & $-2 \%$ & $38 \%$ \\
\hline Goiânia & Física & Lic. & Vesp. & $*$ & * & $*$ & $*$ \\
\hline Goiânia & Matemática & Lic. & Not. & $55 \%$ & $65 \%$ & $23 \%$ & $48 \%$ \\
\hline Goiânia & Matemática & Lic. & Vesp. & $-21 \%$ & $46 \%$ & $-31 \%$ & $-2 \%$ \\
\hline Goiânia & Química & Lic. & Int. & $25 \%$ & $56 \%$ & $63 \%$ & $48 \%$ \\
\hline Goiânia & Química & Lic. & Not. & $59 \%$ & $58 \%$ & $-7 \%$ & $37 \%$ \\
\hline
\end{tabular}

Observação: * Não contêm dados, cursos que não estavam ativos no ano referenciado. Fonte: Elaborado pela autora com os dados da pesquisa

Para a construção da Tabela 2, foi utilizada a equação 1 (proposta pela CEEE).

Da análise da tabela 2, verificou-se que o curso que teve uma maior taxa de evasão foi o curso de Física (habilitação em licenciatura, no período integral, da Regional Goiânia da UFG) com taxa de evasão de 94\%, seguido pelo curso de Física (habilitação em licenciatura, no período noturno, da Regional Jataí da UFG) com taxa de evasão de $81 \%$ e em terceiro lugar ficou o curso de Química (habilitação em licenciatura, no período noturno, da Regional Jataí da UFG) com uma taxa de evasão média de $72 \%$. Enquanto o curso que apresentou a menor evasão foi o curso de Química (habilitação em licenciatura, no período noturno, da Regional Catalão da UFG) com uma taxa de 29\% de evasão média. 
Tabela 2 - Taxas de evasão por curso (em ordem alfabética) e de evasão média anual, entre os anos de 2014 a 2016, de acordo com a fórmula da FORPLAD.

${ }^{\star} \mathrm{TE} / 14$ = taxa de evasão no ano de 2014,

**TE/15 = taxa de evasão no ano de 2015 ,

${ }^{* * *} \mathrm{TE} / 16$ = taxa de evasão no ano de 2016

\begin{tabular}{|c|c|c|c|c|c|c|c|}
\hline $\begin{array}{l}\text { Regional/ } \\
\text { Câmpus }\end{array}$ & Curso & $\begin{array}{c}\text { Grau } \\
\text { Acadêmico }\end{array}$ & Turno & TE/14* & $\mathrm{TE} / 15^{* *}$ & $\begin{array}{c}\mathrm{TE} / 16^{* *} \\
*\end{array}$ & $\begin{array}{l}\text { Evasão } \\
\text { média }\end{array}$ \\
\hline Catalão & Física & Lic. & Not. & $25 \%$ & $72 \%$ & $37 \%$ & $45 \%$ \\
\hline Catalão & Matemática & Lic. & Not. & $38 \%$ & $37 \%$ & $17 \%$ & $30 \%$ \\
\hline Catalão & Química & Lic. & Not. & $8 \%$ & $22 \%$ & $10 \%$ & $13 \%$ \\
\hline Jataí & Física & Lic. & Not. & $80 \%$ & $104 \%$ & $53 \%$ & $79 \%$ \\
\hline Jataí & Matemática & Lic. & Not. & $64 \%$ & $92 \%$ & $32 \%$ & $63 \%$ \\
\hline Jataí & Química & Lic. & Not. & $53 \%$ & $80 \%$ & $71 \%$ & $68 \%$ \\
\hline Goiânia & Física & Lic. & Int. & $25 \%$ & $49 \%$ & $44 \%$ & $40 \%$ \\
\hline Goiânia & Física & Lic. & Not. & $55 \%$ & $32 \%$ & $32 \%$ & $40 \%$ \\
\hline Goiânia & Física & Lic. & Vesp. & $8 \%$ & $20 \%$ & $-1 \%$ & $9 \%$ \\
\hline Goiânia & Matemática & Lic. & Not. & $26 \%$ & $21 \%$ & $23 \%$ & $23 \%$ \\
\hline Goiânia & Matemática & Lic. & Vesp. & $16 \%$ & $20 \%$ & $8 \%$ & $15 \%$ \\
\hline Goiânia & Química & Lic. & Int. & $20 \%$ & $33 \%$ & $37 \%$ & $30 \%$ \\
\hline Goiânia & Química & Lic. & Not. & $19 \%$ & $33 \%$ & $32 \%$ & $28 \%$ \\
\hline
\end{tabular}

Fonte: Elaborado pelos próprios autores com os dados da pesquisa

Da análise da tabela 3, em que se utilizou o método de cálculo sugerido pelo FORPLAD (Equação 2), verificou-se que o curso que apresentou a maior taxa de evasão foi o curso de curso de Física (habilitação em licenciatura, no período noturno, da Regional Jataí da UFG) com taxa média de 79\% de evasão, seguido do curso de Química (habilitação em licenciatura, no período noturno, da Regional Jataí da UFG) com taxa de 68\% e em terceiro lugar o curso de curso de Matemática (habilitação em licenciatura, no período noturno, da Regional Catalão da UFG) com 63\% de evasão média. No outro extremo, encontra-se o curso de Física (habilitação em licenciatura, no período vespertino, da Regional Goiânia da UFG) com 9\% de evasão média, sendo este o curso com a menor taxa evasão entre os cursos estudados no período de 2014 e 2016.

\subsection{Metodologia qualitativa do mapeamento da evasão dos cursos de licenciaturas da UFG}

Os cálculos efetuados pelas equações 1 (proposta pela CEEE) e 2 (FORPLAD), apenas provaram que efetivamente houve evasão e a sua percentagem média por curso, mas não forneceram respostas, por exemplo: de que nível de aluno se evadiu?; qual a razão que poderia estar em causa por trás da evasão?

Ou seja, houve imensa insatisfação com estes resultados. 
Assim, a metodologia que se pretendeu apresentar, envolveu três etapas específicas: a pesquisa bibliográfica, pesquisa transversal e pesquisa documental.

Os objetivos e a(s) questão(ões) de investigação, foram explicitados na tabela 5.

Para a realização deste estudo, foi escolhida a Universidade Federal de Goiás/ Regional Catalão (UFG/RC), localizada no extremo sul do estado de Goiás-Brasil. Essa IES, à data do estudo, possuía uma composição multicampi (possui campus nas cidades de Catalão, Cidade de Goiás, Goiânia e Jataí). A UFG/RC oferecia 26 cursos (habilitações) de graduação distribuídos em praticamente todas as grandes áreas do conhecimento. É importante informar que a pesquisa desenvolvida contou com autorização formal da Instituição bem como com a anuência da coordenação dos cursos.

\subsubsection{Participantes}

Para cálculo das amostras foi utilizada a calculadora estatística disponibilizada pelo sítio Openepi ${ }^{1}$, que possuía uma margem de erro de $5 \%$ e intervalo de confiança de 95\%, tanto para os estudantes (caloiros, ingressantes e evadidos). Os valores das amostras são apresentados na tabela 4.

Tabela 4 - Cálculo das amostras de estudantes (calouros/veteranos e evadidos)

\begin{tabular}{cccc}
\hline Sujeitos da pesquisa & População (2016/2) & Amostra calculada & Amostra obtida \\
\hline Calouros/veteranos & 21.836 & 378 & $227 / 689$ \\
\hline Evadidos & 20.660 & 378 & 222 \\
\hline
\end{tabular}

Fonte: Elaborado pelos próprios autores com os dados da pesquisa

\subsubsection{Instrumentos de recolha de dados}

Para esta pesquisa foram desenvolvidos e utilizados 05 (cinco) instrumentos/documentos na recolha de dados:

i. 4 (quatro) questionários contendo questões fechadas (utilizando a escala Likert) e questões abertas (Santos Souza, 2017);

ii. Termo de Consentimento Livre e Esclarecido - TCLE, de acordo com a Resolução CNS 466/2012 (Santos Souza, 2017).

\subsubsection{Recolha e tratamento de dados qualitativos}

Tendo em vista os objetivos deste estudo, (ver tabela 5), procurou-se uma descrição pormenorizada e rigorosa, de forma a garantir a validação e/ou a credibilidade de um estudo qualitativo (Amado, 2013). Alguns autores (Sá \& Costa, 2016, p. 9) referiraram-se "à necessidade de estabelecer algumas estratégias. Entre elas, destacaram-se 
a triangulação das várias fontes recolhidas, ou seja, olhar para o mesmo fenómeno de diferentes ângulos"; optou-se ainda por privilegiar a triangulação de dados - modalidade que comprova se as informações recolhidas são confirmadas por outra fonte (teórica), e recorreu-se à transparência de todo o processo que garante ao leitor o mérito, a credibilidade e a confiabilidade da investigação (Souza, Costa, \& Souza, 2015, p. 151).

\subsubsection{Questões abertas nos questionários}

A partir dos dados das três questões abertas do questionário (Santos Souza, 2017), e do apoio na literatura houve uma orientação destinada a garantir níveis adequados de consistência entre as informações recolhidas. A análise foi elaborada tendo como principais referências a matriz da investigação, a questão de investigação e os objetivos. Desta forma, procurou-se igualmente garantir a consistência necessária relativa à formulação de questões consideradas críticas e/ou fundamentais, para não se comprometer os objetivos centrais do estudo.

Com as questões colocadas aos alunos caloiros, veteranos e evadidos procurou-se obter vários esclarecimentos, nomeadamente, mapear as razões da evasão nos cursos presenciais de licenciatura em Física, Matemática e Química.

De acordo com outros autores (Esteves, 2006; Holsti, 1969; Quivy \& Campenhoudt, 2003), a análise de conteúdo pareceu o processo mais adequado para proceder ao tratamento dos testemunhos e informações recolhidas.

O processo de análise de conteúdo iniciou-se com uma "leitura flutuante" (Bardin, 2004), dos corpora dados, a fim de estabelecer um primeiro contato com os documentos, seguiram-se posteriores leituras - dada a riqueza e extensão do corpus analisado. Após esta fase, começaram a emergir as grandes categorias, de forma indutiva, conforme os objetivos pré-estabelecidos, o quadro teórico e o resultado das questões. Encontrou-se duas categorias: Instituição e Fatores endógenos; bem como quinze (15) subcategorias: Professores, Curso, Aulas, Ensino, Horário, Coordenação de Curso, Transporte, Trabalho, Problemas, Matérias, Tempo, Família, Realização pessoal, Realização profissional e Mudança de Curso, ver tabela 6.

Com a ajuda do software webQDA $®$ (Costa, Moreira \& Souza, 2019), incluíu-se os dados (respostas dadas nas questões abertas pelos caloiros, veteranos e evadidos) nas fontes, seguida das codificações, onde construíu-se a árvore com as dimensões e subcategorias e, por último, o questionamento, onde se questionou os dados para dar resposta à(s) questão(ões) de investigação.

\subsubsection{A matriz de análise qualitativa}

Teve-se consciência, à partida, das características próprias de cada comunidade e das grandes diferenças relativamente ao quadro teórico. Assim, foi de grande importância, a criação de uma matriz de análise homogénea que visasse três objetivos: 
a) não perder de vista as questões de investigação; b) permitir uma triangulação e comparação entre os vários corpora de dados; c) possibilitar a comparação entre contextos, ver tabela 5.

A matriz então criada demonstrou-se facilitadora destes objetivos e apresenta-se a seguir:

Tabela 5 - Coerência interna da investigação para a Dimensão "Aprendizagem do aluno"

\begin{tabular}{|c|c|c|c|c|}
\hline $\begin{array}{l}\text { Questão(ões) de } \\
\text { investigação }\end{array}$ & $\begin{array}{l}\text { Objetivo de } \\
\text { investigação }\end{array}$ & Corpus de dados & $\begin{array}{l}\text { Tipos de } \\
\text { Análise }\end{array}$ & $\begin{array}{l}\text { Observações e } \\
\text { Expectativas }\end{array}$ \\
\hline $\begin{array}{l}\text { Qual(is) o(s) real(is) } \\
\text { motivo(s) que leva(m) } \\
\text { o estudante a } \\
\text { abandonar o seu curso } \\
\text { de licenciaturas na } \\
\text { UFG? }\end{array}$ & $\begin{array}{l}\text { Analisar as causas } \\
\text { da evasão nos } \\
\text { cursos presenciais } \\
\text { de graduação na } \\
\text { UFG. }\end{array}$ & $\begin{array}{l}\text { Respostas aos } \\
\text { questionários } \\
\text { pelos calouros, } \\
\text { veteranos e } \\
\text { evadidos. }\end{array}$ & $\begin{array}{l}\text { Análise de } \\
\text { Conteúdo }\end{array}$ & $\begin{array}{l}\text { Esperamos poder } \\
\text { comparar os dados das } \\
\text { respostas dos calouros } \\
\text { e correlacioná-los com } \\
\text { os veteranos } \\
\text { evadidos. }\end{array}$ \\
\hline
\end{tabular}

Fonte: Elaborado pelos próprios autores com os dados da pesquisa

\section{Apresentação e Discussão de Resultados}

Assim, apresentou-se e discutiu-se os dados obtidos a partir da triangulação entre o conteúdo das respostas das três questões aos caloiros, veteranos e evadidos. Com a ajuda do software webQDA $®$, a homogeneidade da categorização resultou da homogeneidade da fonte de documentos, pois as respostas são testemunhos escritos, resultantes da interpretação pessoal dos entrevistados sobre o objeto em questão, pelo que a categorização resultou, sobretudo, de dados emergentes da análise das respostas. A análise desta variedade de fontes de dados foi organizada e sistematizada por meio de uma árvore de categorias, ver figura 1, permitindo aos investigadores o registo de todo o contexto da investigação, questionar os dados e classificar relações (Souza, Costa, \& Souza, 2015). 


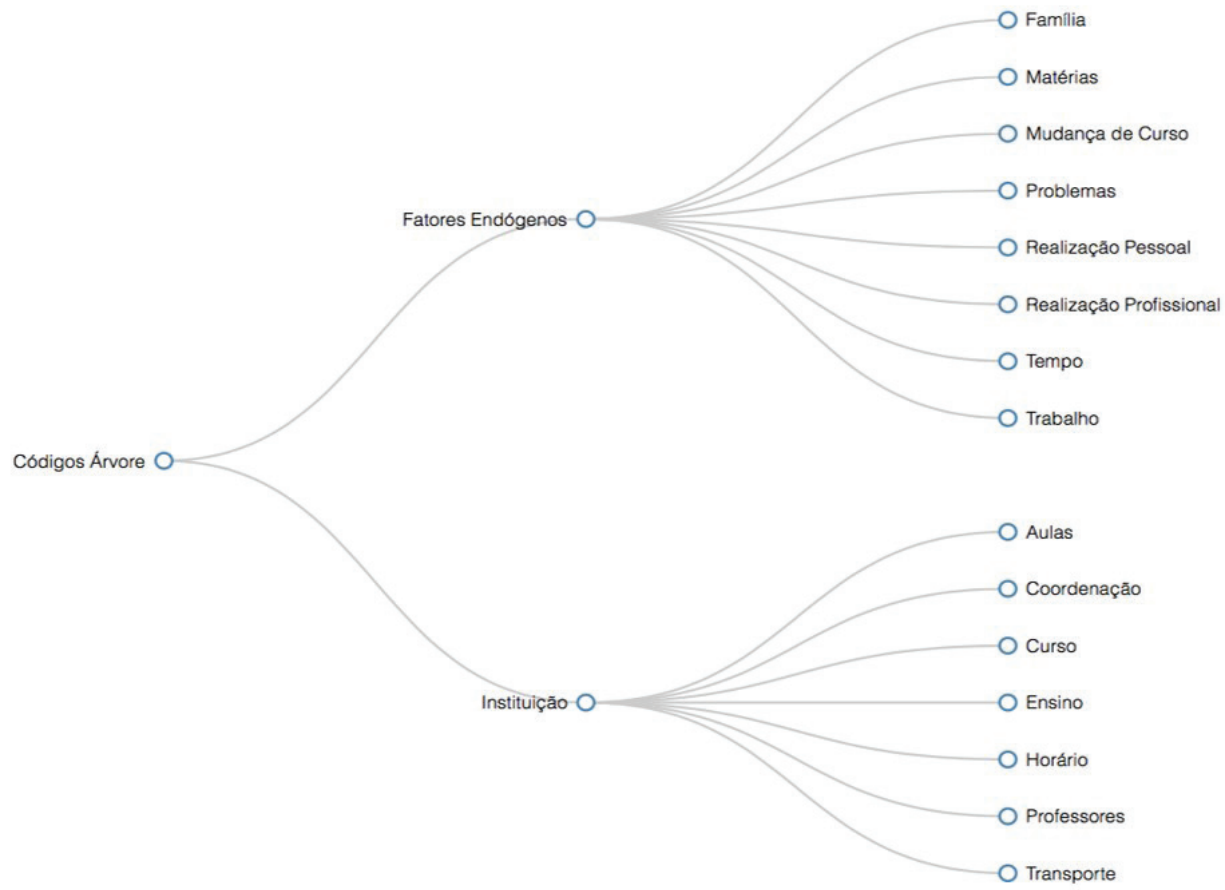

Figura 1 - Árvore de categorias

Fonte: Elaborado pelos próprios autores com os dados da pesquisa

Assim, de modo a organizar e clarificar a apresentação dos resultados e demonstrar a coerência interna da investigação, fez-se a análise das respostas por objetivos de investigação, seguidas de discussão e de uma síntese para aglutinar ideias e destacar os resultados essenciais para a investigação em causa, tentando dar uma resposta às perguntas de investigação, tal como se mostra na tabela 6. 
Tabela 6 - Categorias e Sub-categorias e definição dos Indicadores

\begin{tabular}{|c|c|c|}
\hline Categorias & Sub- categorias & Indicadores \\
\hline \multirow{7}{*}{ Instituição } & Professores & $\begin{array}{l}\text { Através da hierarquia formal, a emissão e a recepção da } \\
\text { informação, poderá causar constrangimentos a nível de relações } \\
\text { interpessoais. }\end{array}$ \\
\hline & Curso & $\begin{array}{l}\text { A estruturação do modo como o curso está num nível de ensino } \\
\text { desadequado (cognitivamente muito mais elevado) da passagem } \\
\text { do ensino médio. }\end{array}$ \\
\hline & Aulas & Aulas desmotivantes. Simples transmissão do saber. \\
\hline & Ensino & $\begin{array}{l}\text { Apenas há a preocupação com o ensino e não com a } \\
\text { aprendizagem. }\end{array}$ \\
\hline & Horário & Pode não ser compatível com a vida externa do estudante. \\
\hline & Coordenação & $\begin{array}{l}\text { Os Professores Coordenadores dos Cursos têm um papel ativo na } \\
\text { instituição no sentido da mediação entre aluno-aluno e aluno- } \\
\text { Professor }\end{array}$ \\
\hline & Transporte & $\begin{array}{l}\text { Os alunos residem longe das instalações da Universidade e } \\
\text { necessitam de utilizar transportes públicos }\end{array}$ \\
\hline \multirow{8}{*}{$\begin{array}{l}\text { Fatores } \\
\text { Endógenos }\end{array}$} & Trabalho & Os alunos acumulam o estudo com trabalho profissional. \\
\hline & Problemas & $\begin{array}{l}\text { São questões de ordem pessoal que poderão afetar decisões e } \\
\text { desempenho, de ordem económica, familiar, saúde, etc. }\end{array}$ \\
\hline & Matérias & $\begin{array}{l}\text { As disciplinas estudadas poderão estar ajustadas ou não ao que os } \\
\text { estudantes esperam do curso. }\end{array}$ \\
\hline & Tempo & $\begin{array}{l}\text { O fator tempo é referido no sentido de assimilação das matérias } \\
\text { que estudam }\end{array}$ \\
\hline & Família & O apoio familiar e a opção familiar pela escolha do curso. \\
\hline & $\begin{array}{c}\text { Realização } \\
\text { Pessoal }\end{array}$ & $\begin{array}{l}\text { A frequência no curso deve-se apenas a questões de âmbito de } \\
\text { realização pessoal na subida de hierarquia social. }\end{array}$ \\
\hline & $\begin{array}{l}\text { Realização } \\
\text { Profissional }\end{array}$ & $\begin{array}{l}\text { A frequência no curso deve-se apenas a questões de âmbito de } \\
\text { realização profissional na subida de escalões de vencimentos. }\end{array}$ \\
\hline & $\begin{array}{l}\text { Mudança de } \\
\text { Curso }\end{array}$ & $\begin{array}{l}\text { Opção pessoal de mudança por estar inscrito em duas } \\
\text { universidades em simultâneo ou ter saído bolsa de estudo. }\end{array}$ \\
\hline
\end{tabular}

Fonte: Elaborado pelos próprios autores com os dados da pesquisa

Ao longo da discussão dos resultados, utilizou-se o termo unidade de referência como unidades de registo, que pode ser a frase ou conjunto de palavras que façam sentido e tenham significado. Para se cumprir o que se propôs, apresentou-se no Gráfico 1, a matriz resultante das unidades de referência dos vários indicadores na triangulação entre os evadidos e mudança de curso. 


\section{Causas dos evadidos de cursos}

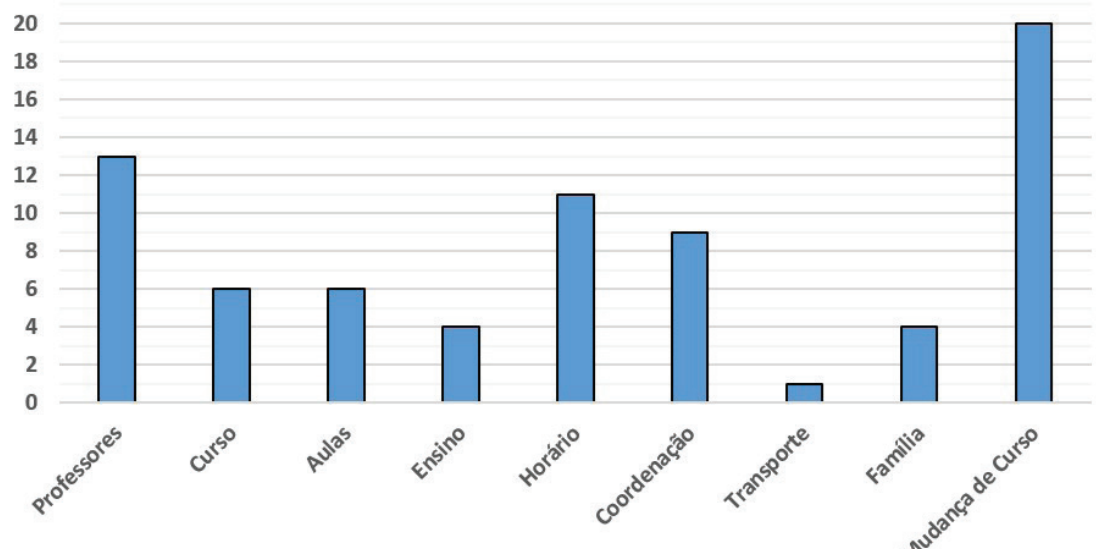

Gráfico 1 - Matriz resultante entre os evadidos e a evasão de curso Fonte: Elaborado pelos próprios autores com os dados da pesquisa

Das categorias verificadas, destacaram-se as de "Professores", "Curso" e "Aula", teve-se como exemplo de resposta: "Professores sem contexto para ministrar aulas no curso de licenciatura... a maioria.", ou "Falta de ética de alguns professores."; na categoria "Curso" obtiveram-se 6 unidades de referência: "falta de experiência, maturidade."; "Não me identifiquei com o curso.". O que veio corroborar o que, já em 1975, Tinto (1975), defendeu, ou seja, os fatores externos, em que o estudante já possui objetivos pré-estabelecidos à entrada da Universidade, conforme as suas necessidades pessoais, sejam elas motivadas pela sua condição financeira, expetativa dos pais, crenças ou valores. O que provocou ao longo da vivência académica, uma desistência da sua vida académica.

Na subcategoria "Aulas", encontrou-se 6 unidades de referência: "Formas antiquadas de ensino.". Na subcategoria "Ensino", encontrou-se 4 unidades de referência: "Professores mais presentes com uma didática atualizada, recessos menores eles tiram a motivação, excesso de trabalhos em grupo é muito difícil dedicar tempo para encontros com colegas para organizar trabalhos que poderiam ser organizados individualmente sem perdas."; "Professores mais responsáveis (que comparecessem as aulas), com didática melhor e que nos deixassem fazer perguntas e sanassem nossas dúvidas". Veio corroborar a precariedade das condições oferecidas pela Universidade no sentido endógeno: preparação curricular e pedagógica dos docentes, as dificuldades académicas e rigidez excessiva dos professores.

$\mathrm{Na}$ categoria Fatores Endógenos, verificou-se que apenas existiram referências na subcategoria "Problemas" com 2 unidades de referência: "Gravidez gemelar, gêmeas 
recém-nascidas, crianças sem a devida autonomia para ficarem com outros."; "problemas financeiros, falta de trabalho". São fatores a ter em conta, mas corroboraram as ideias de obrigações sociais, impossibilidade de estudar e trabalhar ao mesmo tempo ou vocação errada.

Ao analisar-se a opinião dos caloiros, verificou-se que a razão mais presente foi a subcategoria "familiar" com 2 unidades referências: "Influencia de familiares", sendo que as outras: o transporte, o curso e os professores, com 1 unidade de referência cada, tal como se pode verificar no gráfico 2.

\section{Causas explanadas pelos alunos}

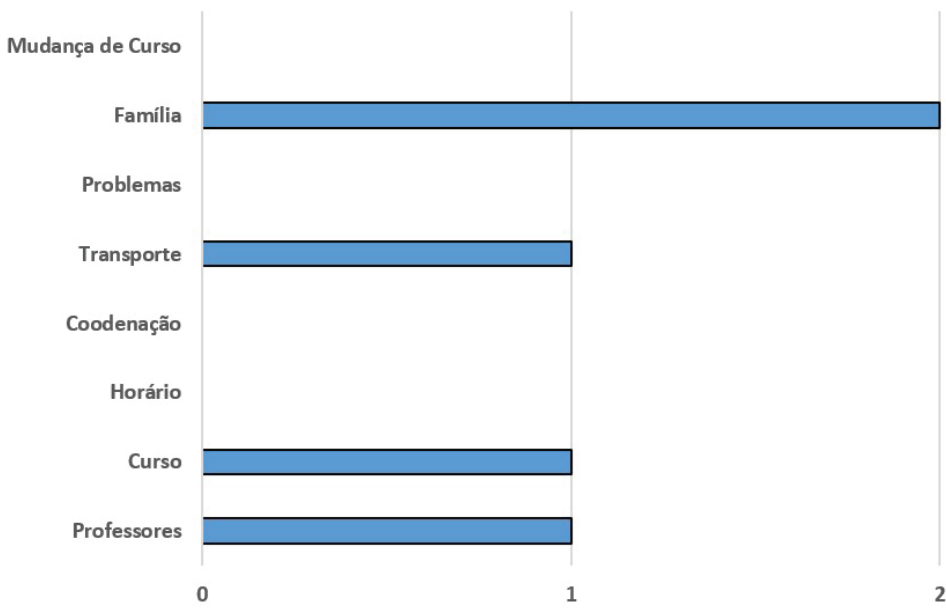

Gráfico 2 - Causas explanadas pelos caloiros para a evasão de curso Fonte: Elaborado pelos próprios autores com os dados da pesquisa

Que veio corroborar a imaturidade dos jovens e a participação/exigência da família por certa escolha profissional do filho.

Passando para a análise dos veteranos, quando confrontados com a questão "Se desistissem do curso, qual seria o motivo?”, (uma matriz, ver gráfico 3), que traduziram as unidades de referência dos vários indicadores na triangulação entre os veteranos e mudança de curso, 


\section{Causas de evasão indicadas por alunos veteranos}

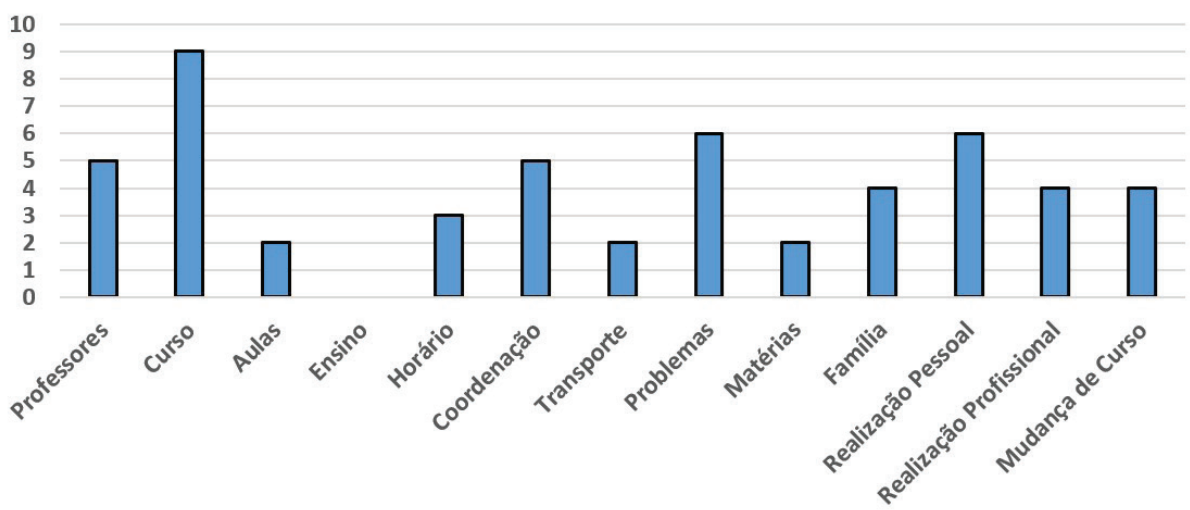

Gráfico 2 - Causas de evasão indicadas por alunos veteranos

Fonte: Elaborado pelos próprios autores com os dados da pesquisa

Do Gráfico 3, verificou-se que os veteranos apontaram as subcategorias "Realização Pessoal" e "Realização Profissional" apesar destas razões seres similares. No caso da subcategoria "Realização Pessoal" encontrou-se 6 unidades de referência: "Mais fácil de arranjar emprego como professora", e na subcategoria "Realização Profissional", encontrou-se 4 unidades de referências: "Melhor hipótese de ter melhor vida". Nesta última categoria, foram os alunos do sexo masculino que referiram apenas esta opção. A subcategoria mais apontada foi o curso em si, com 9 unidades de referência, no sentido de não ser o curso pretendido. Veio corroborar a impossibilidade de estudar e trabalhar ao mesmo tempo. Por outro lado, realçaram o aspecto do status económico e social por tirarem uma licenciatura: a) uma maior empregabilidade; b) realização pessoal e c) realização profissional.

\section{Considerações Finais}

No Brasil, assim como em muitos outros países, o sistema de ensino coloca em vantagem os representantes de grupos sociais mais elevados. Neste contexto, este nível de ensino, contribuiu para esse estatuto social. Por outro lado, houve uma relação direta entre grupo social elevado e profissão, assim, aceder a uma melhor profissão poderá ser um passaporte para essa tão desejada ascensão social. Como já discutido anteriormente, nem sempre os estudantes escolhem o curso por vocação, mas sim por influências exógenas ou outras razões, nas relações: a) pessoais e b) profissionais. Assim, teve-se a percepção, com base nos resultados, de que os estudantes sentem falta de um acompanhamento pedagógico/psicológico/orientação vocacional, executado por 
profissionais credenciados, na sua instituição de Ensino Superior, para poderem colmatar alguns desaires ou "frustrações" logo à partida no início das aulas no curso.

Conclui-se, tal como corroboram os estudos de Silva e colaboradores (2016), Sá (2015) e Ruiz e colaboradores (2007), Tinto (1975), Carvalho e Tafner (2006) e Bergamo e colaboradores (2008) os principais fatores/causas para a evasão (abandono) no Ensino Superior, os alunos citaram os: a) Professores; b) Coordenação; c) Ensino e d) Aulas.

É preocupante verificar-se que a evasão dos alunos foi devido a causas como o Ensino ministrado pelos Professores e por consequência as aulas serem, nos dias de hoje, desmotivadoras. Hoje que há recursos para os mais diversos métodos de ensino-aprendizagem em que o centro do processo é o aluno (Sá, 2015).

Estas causas terão de ser objeto de reflexões e de estudos mais aprofundados para se poder aperceber onde realmente estão os fatores causadores de insatisfação citados.

A partir dos resultados obtidos neste trabalho, foi possível verificar que o cenário das altas taxas de evasão nos cursos de Física, Matemática e Química, são os mesmos citados pelo estudo de Ruiz e colaboradores (2007), ou seja, a situação permanece inalterada depois de uma década.

Por fim, as conclusões do estudo corroboraram as dos estudos de Carvalho e Tafner (2006) e Silva e colaboradores (2016). Encontrou-se mais perto do trabalho de Silva e colaboradores (2006), efetuado em várias universidades portuguesas, exceto na questão da idade e de género, uma vez que no estudo realizado refere-se a alunos mais velhos que apresentaram maior evasão nas licenciaturas em estudo.

Uma das primeiras e mais importantes considerações a que se chegou com este estudo foi a de que, apesar de ter sido possível recolher dados e verificar/esclarecer algumas questões, este artigo não esgotou o tema. Outros estudos que abordam a temática "evasão" deverão ser realizados, ou seja, verificou-se uma grande necessidade de continuidade deste estudo, inclusive, com o análise/estudo e implementação de programas/política da(s) universidade(s) com objetivo de reduzir/eliminar a evasão, não só com a participação do corpo docente, mas principalmente com a dos estudantes ingressantes, veteranos e, em particular e em especial, com os evadidos que poderão expressar todas as dificuldades encontradas ao longo de todo trajeto do curso, seja com sucesso ou insucesso.

\section{Notas}

1 http://www.openepi.com/SampleSize/SSPropor.htm

\section{Referências}

Amado, J. (2013). Manual de Investigação Qualitativa em Educação. Coimbra: Imprensa da Universidade de Coimbra. 
Andriola, W. B. (2003). Evasão discente na Universidade Federal do Ceará (UFC): proposta para identificar causas e implantar um serviço de orientação e informação (SOI). Ensaio: avaliação e políticas públicas em Educação, 11, (40), 332-347.

Bardagi, M. P. \& Hutz, C. S. (2008). Apoio parental percebido no contexto da escolha inicial e da evasão de curso universitário. Revista Brasileira de orientação profissional, 9, (2), 31-44.

Bardin, L. (2004). Análise de Conteúdo. Lisboa: Edições 70.

Bergamo, F. V. M., Ponchio, M. C., Zambaldi, F., Giuliani, A. C., \& Spers, E. E. (2008). De prospect a aluno: Fatores influenciadores da escolha de uma Instituição de Ensino Superior. Curitiba:Encontro de Marketing da Anpad3.

Carvalho, M., \& Tafner, P. (2006). Ensino Superior Brasileiro: a evasão dos alunos e a relação entre formação e profissão. Caxambu. Disponível em https://anpocs.com/index.php/encontros/ papers/30-encontro-anual-da-anpocs/gt-26/gt06-10/3251-carvalho-tafner-ensino/file. Acesso em: 21 de maio de 2017.

Costa, A., Moreira, A. \& de Souza, F. (2019). webQDA (version 3.1) - Qualitative Data Analysis. Aveiro University and MicrolO, Aveiro - Portugal.

Esteves, M. (2006). Análise de Conteúdo. In Lima, J. A. \& Pacheco, J. A., (Orgs.). Fazer Investigação Contributos para a elaboração de dissertações e teses. Porto: Porto Editora.

Filho, R. L. L. S., Motejunas, P. R., Hipólito, O., \& Lobo, M. B. C. M. (2007). A evasão no ensino superior brasileiro. Cadernos de pesquisa, 37, (132), 641-659.

Holsti, O. (1969). Content Analysis for Social Sciences and Humanities. Reading: Addison-Wesley.

Ministério da Educação/Secretaria de Educação Superior (MEC/SESu), (1997). Comissão especial de estudos sobre a evasão nas universidades públicas brasileiras. Brasília: ANDIFES/ABRUEM/SESu/ MEC.

Nunes, R. C. (2013). Panorama geral da evasão e retenção no ensino superior no Brasil. XXVI Encontro Nacional de Pró-reitores de Graduação COGRAD/ANDIFES, Recife, 2013. [Disponível em http:// arquivos.info.ufrn.br/arquivos/201723623308a84006474291af3e089d2/2013_-_Painel_Forgrad_ Agosto_-_Evasao.pdf, consultado em 21/05/2017].

Quivy, R., \& Campenhoudt, L. (2003). Manual de Investigação em Ciências Sociais. Lisboa: Gradiva.

Ruiz, A. I., Ramos, M. N., \& Hingel, M. (2007). Escassez de professores no ensino médio: propostas estruturais e emergenciais. Relatório produzido pela Comissão especial instituída para estudar medidas que visem superar o déficit docente no ensino médio (CNE/CEB). JDisponível em http:// portal.mec.gov.br/cne/arquivos/pdf/escassez1.pdf, consultado em 21/05/2017].

Sá, S. (2015). Ensino, Aprendizagem e Avaliação no Ensino Superior: Perspetivas e Práticas. Tese de doutoramento não publicada, Braga: Universidade do Minho.

Sá, S. O., \& Costa, A. P. (2016). Critérios de Qualidade de um Estudo Qualitativo (Carta Editorial). Revista Eixo, 5(3), 9-12.

Santos Souza, T. (2017). Estudo sobre a Evasão em Cursos de Graduação Presenciais na Universidade Federal de Goiás - UFG. 2017. 219 f. (Dissertação Mestrado). Universidade Federal do Goiás, Regional Catalão - UFG/Regional Catalão. 
Silva, S., Ramalho, N., Passos, A., Caetano, A., Seixas, A., \& Santos, A. (2016). Abordagens do sucesso, insucesso e abandono no ensino superior. J. Mendes, A. Caetano \& J. Ferreira (Orgs.). Sucesso e abandono no ensino superior em Portugal, (pp. 19-46), Coimbra: Edições Almedina.

Souza, N. de, Costa, A. P., \& Souza, F. de (2015). Desafio e inovação do estudo de caso com apoio das tecnologias. (Vol. 2). In F. de Souza, D. de Souza \& A. P. Costa (Orgs.), Investigação Qualitativa: Inovação, Dilemas e Desafios, (pp. 143-162), Oliveira de Azeméis, Aveiro: Ludomedia.

Tinto, V. (1975). Dropout from higher education: a theoretical synthesis of recent research. Review of Educational Research, 45, 89-125.

Veloso, T. (2000). Evasão nos Cursos de Graduação da Universidade Federal de Mato Grosso, Campus Universitário de Cuiabá 1985/2 a 1995/2 - Um processo de Exclusão. 2000. (Dissertação Mestrado). Universidade Federal do Mato Grosso, Cuiabá - UFMT.

Thays Santos Souza

Mestre em Gestão Organizacional; Universidade Federal de Goiás -

Regional Catalão, Brasil.

thays.adm21@gmail.com

ORCID: https://orcid.org/0000-0002-8208-3246

Susana Sá

Centro de Investigação de Estudos da Criança da Universidade do Minho,

Portugal. susanaemiliasa@gmail.com ORCID: https://orcid.org/0000-0003-1339-5745

Paulo Alexandre de Castro Departamento de Física; Universidade Federal de Goiás - Regional Catalão, Brasil. Mestrado em Gestão Organizacional; Universidade Federal de Goiás - Regional Catalão, Brasil. padecastro@gmail.com ORCID: https://orcid.org/0000-0001-7746-7184

Correspondência

Paulo Alexandre de Castro Departamento de Física; Universidade Federal de Goiás - Regional Catalão, Brasil. Mestrado em Gestão Organizacional; Universidade Federal de Goiás - Regional Catalão, Av. Dr. Lamartine Pinto de Avelar, 1120 - St. Universitário, Catalão - GO, 75704-020 - Brasil.

Data de submissão: Setembro de 2017

Data de avaliação: Novembro de 2017

Data de publicação: Julho 2018 